\title{
Hyperkalaemia in diabetes: prevalence and associations
}

\author{
PR Jarman, AM Kehely, HM Mather
}

\begin{abstract}
Summary
Hyperkalaemia is associated with diabetes, but there are no recent reports of its prevalence and associations. Serum potassium concentrations were measured in all 1764 patients attending a diabetic clinic over a 12-month period and found to be $>5.0 \mathrm{mmol} / 1$ in $270(15 \%)$, and $>5.4 \mathrm{mmol} / 1$ in 67 (4\%). There was no other evident cause of hyperkalaemia in 41 of these 67 patients. These data serve to highlight the risk of dangerous hyperkalaemia in diabetic patients, particularly with concurrent administration of angiotensin-converting-enzyme inhibitors and potassium-sparing diuretics.
\end{abstract}

Keywords: hyperkalaemia, diabetes

Hyperkalaemia is known to be associated with diabetes, and dangerous hyperkalaemia has been described in diabetic patients following the use of potassium-sparing diuretics. ${ }^{1}$ It may become more common because of the accumulating evidence of specific benefit con(ACE) inhibitor drugs in the treatment of diabetic hypertension and nephropathy. However, there are no modern studies of the prevalence of hyperkalaemia in diabetic patients. We therefore measured serum potassium $(\mathrm{K})$ concentrations in all patients attending a hospital clinic over a 12-month period, and examined its associations.

\section{Patients and methods}

All 1764 patients attending a hospital diabetic clinic over a 12-month period were studied. Blood specimens were centrifuged and separated within 30 minutes, and serum potassium analysed using an ion-selective electrode in the Hitachi 717 Auto-analyzer. Differences in means were tested using $t$-tests, and differences in proportions with the chi-square test.

Ealing Hospital, Southall, Middlesex UB1 3HW, UK

PR Jarman

AM Kehely

HM Mather

Correspondence to HM Mather

\section{Results}

Serum $\mathrm{K}$ concentration was $>5.0 \mathrm{mmol} / \mathrm{l}$ in $270(15 \%)$ of 1764 patients, $>5.4 \mathrm{mmol} / 1$ in 67 $(4 \%),>5.6 \mathrm{mmol} / 1$ in $26(1 \%)$ and $>6.0 \mathrm{mmol} / 1$ in six patients. Our laboratory normal range is $3.5-5.0 \mathrm{mmol} / 1$. Serum $\mathrm{K}$ was below $3.4 \mathrm{mmol} / 1$ in only four patients. The ferred by angiotensin-converting enzyme

correlation coefficients between serum $K$ and various biochemical and clinical variables are listed in table 1 . Weak but significant correlations were observed with serum urea, serum creatinine, known duration of diabetes, age and $\mathrm{HbAl}$, but there was no significant correlation with plasma glucose.

There were significant relationships between mean serum $K$ and the presence of nephropathy and retinopathy. Mean serum $\mathrm{K}$ was significantly higher in patients with retinopathy or heavy proteinuria than in the remainder, and increasing severity of proteinuria and retinopathy were both associated with an increase in mean serum $\mathrm{K}$ (table 2 ). This could not be attributed solely to renal impairment, because the mean $\mathrm{K}$ was significantly elevated in those patients with retinopathy requiring laser treatment whose serum creatinine was less than $140 \mu \mathrm{mol} / 1$. There were no significant differences in mean $K$ between patients treated with insulin, oral hypoglycaemic drugs, or diet alone.

Fourteen of the 67 patients whose serum $K$ was $>5.4 \mathrm{mmol} / 1$ were receiving drug therapy which might have contributed to the hyperkalaemia (six taking ACE inhibitor drugs, five potassium-sparing diuretics, and three nonsteroidal anti-inflammatory drugs). Serum creatinine was greater than $140 \mu \mathrm{mol} / 1$ in 12 other patients. In the remaining 41 patients, there was no other evident cause for their hyperkalaemia. Their clinical features were compared with the remainder of the clinic population. A similar proportion of both groups had retinopathy (24\% vs $18 \%$, ns) and proteinuria $(15 \%$ vs $12 \%, \mathrm{~ns})$, and there was no significant difference in mean age, mean known duration of diabetes, or the proportions receiving insulin treatment. Only seven of the 41 patients had clinically evident neuropathy, and only two had clinically evident autonomic neuropathy.

Table 1 Correlations between serum potassium concentration and other variables 
Table 2 The associations between mean serum potassium concentration and proteinuria and retinopathy

\begin{tabular}{lrlll}
\hline & & \multicolumn{3}{l}{ Serum $K^{+}$concentration $($mmol/l) } \\
\cline { 3 - 5 } & $n$ & mean & $S D$ & $p^{\star}$ \\
\hline no proteinuria & 1524 & 4.59 & 0.45 & - \\
proteinuria '+' & 108 & 4.63 & 0.41 & ns \\
proteinuria '++' & 74 & 4.76 & 0.54 & $<0.05$ \\
proteinuria '+++' & 21 & 4.86 & 0.74 & $<0.01$ \\
no retinopathy & 1323 & 4.56 & 0.43 & - \\
background retinopathy & 138 & 4.68 & 0.47 & $<0.01$ \\
severe retinopathy $\star \star$ & 188 & 4.80 & 0.45 & $<0.001$ \\
history of laser therapy & 97 & 4.76 & 0.40 & $<0.001$ \\
$\quad$ and creatinine $>140 \mu \mathrm{mol} / 1$ & & & &
\end{tabular}

$\star$ = significance of difference between patients with no proteinuria or retinopathy and other groups.

$\star \star=$ maculopathy, proliferative retinopathy or history of laser therapy

\section{Discussion}

This study shows that hyperkalaemia is relatively common in unselected diabetic outpatients, even when there is no significant elevation of serum urea or creatinine, and even in the absence of drugs known to elevate potassium levels. Although this finding is wellrecognised by most diabetologists, there have been no recent estimates of its prevalence or associations. Its mechanisms are not fully understood. It cannot be attributed solely to renal impairment because hyperkalaemia is usually associated only with advanced renal failure when the glomerular filtration rate is less than $20 \mathrm{ml} / \mathrm{min}^{2}$ Only 12 of the 67 patients with a markedly elevated serum $K$ $(>5.4 \mathrm{mmol} / \mathrm{l})$ had established renal failure (creatinine concentration $>140 \mu \mathrm{mol} / \mathrm{l}$ ). The differences in mean serum $\mathrm{K}$ between patients with and without microangiopathic complications (proteinuria and severe retinopathy) remained significant even when those with established renal failure had been excluded.

A paradoxical rise in potassium concentration has been found in some diabetic patients following a glucose $\operatorname{load}^{3-5}$ and has been attributed to insulin deficiency and/or resistance. However, there was no correlation in our patients between potassium and glucose concentrations measured simultaneously, and only a weak correlation with HBAl.

Hyporeninaemic hypoaldosteronism has been repeatedly demonstrated in diabetic patients, especially in association with nephropathy and

1 Large DM, Carr PH, Laing I, Davies M. Hyperkalaemia in diabetes mellitus - potential hazards of coexisting hyporeninaemic hypoaldosteronism. Postgrad Med $\mathcal{F} 1984$ 60: $370-3$

2 De Fronzo RA, Sherwin RS, Felig P, Bia M. Nonuremic diabetic hyperkalemia. Arch Intern Med 1977; 137: 842-3. 3 Goldfarb S, Strunk B, Singer I, Goldberg M. Paradoxica glucose-induced hyperkalaemia. Am $\mathcal{F}^{\mathrm{Med}}$ 1975; 59: 744-50.

4 Rosenstock J, Loizou SA, Brajkovich IE, Mashiter K, Joplin GF. Effect of acute hyperglycaemia on plasma potassium and aldosterone levels in type 2 (non-insulin-dependent) diabetes. Diabetologia 1982; 22: 184-7.

5 Shalwitz RA, Gingerich RL, McGill JB, McDonald JM Effect of hyperglycemia on plasma sodium and potassium concentration revisited. Clin Chem 1991; 37: 293-4.
Mechanisms of hyperkalaemia in diabetic out-patients

Drugs

- ACE inhibitors

- potassium-sparing diuretics

- non-steroidal anti-inflammatory agents

Idiopathic

- advanced renal failure

- hyporeninaemic hypoaldosteronism

- paradoxical - related to hyperglycaemia

Artefactual

- delay in sample separation

\begin{tabular}{|l|}
\hline Summary points \\
\hline - hyperkalaemia is not uncommon in diabetic \\
patients \\
although it is weakly associated with \\
microvascular complications, often there is no \\
obvious explanation \\
it is important to bear this in mind before \\
initiating ACE inhibitors or \\
potassium-sparing diuretics
\end{tabular}

retinopathy, ${ }^{6-8}$ and has been proposed as an important factor leading to hyperkalaemia in diabetes. A reduction in $\left(\mathrm{Na}^{+}-\mathrm{K}^{+}\right)$ATPase activity in hyperkalaemic diabetic patients has recently been described, and may also play a role. ${ }^{9}$

The low prevalence of hypokalaemia found in our patients is of interest. Low-dose thiazides (principally as bendrofluazide, $2.5 \mathrm{mg}$ ) are used as first-line treatment for diabetic hypertension in this patient group. Our data confirm that this rarely produces hypokalaemia.

The high prevalence of hyperkalaemia found in this study has practical importance, because of the increasing use of ACE inhibitors to treat diabetic patients with hypertension, nephropathy, and the use of these agents or potassium-sparing diuretics in cardiac failure. Some patients may have unsuspected severe hyperkalaemia before commencing these drugs. It is thus particularly important to check potassium levels when starting diabetic patients on these agents, to reduce the small but real risk of producing dangerous hyperkalaemia.

6 De Fronzo RA. Hyperkalemia and hyporeninemic hypoaldosteronism. Kidney Int 1980; 17 : 118-34.

7 Tan SY, Burton M. Hyporeninemic hypoaldosteronism - an overlooked cause of hyperkalemia. Arch Intern Med 1981; 141: $30-3$.

8 Christlieb AR, Kaldany A, D'Elia JA, Williams GH. Aldosterone responsiveness in patients with diabetes mellitus. Diabetes 1978; 27: 732-7.

9 Mimura M, Makino H, Kanatsuka A, Yoshida S. Reduction of erythrocyte $\left(\mathrm{Na}^{+}-\mathrm{K}^{+}\right)$ATPase activities in non-insulindependent diabetic patients with hyperkalemia. Metabolism 1992; 41: 426-30. 